\title{
SeedChaser: Vertical soil tillage distribution model
}

\author{
K. Spokas ${ }^{\mathrm{a}, *}$, F. Forcella ${ }^{\mathrm{a}}$, D. Archer ${ }^{\mathrm{b}}$, D. Reicosky ${ }^{\mathrm{a}}$ \\ ${ }^{a}$ U.S. Department of Agriculture-Agricultural Research Service (USDA-ARS), North Central Soil Conservation \\ Research Laboratory, 803 Iowa Avenue, Morris, MN 56267, USA \\ ${ }^{\mathrm{b}}$ U.S. Department of Agriculture-Agricultural Research Service (USDA-ARS), Northern Great Plains \\ Research Laboratory, P.O. Box 459, Mandan, ND 58554, USA
}

Received 13 October 2006; received in revised form 30 January 2007; accepted 31 January 2007

\begin{abstract}
Knowledge of the vertical distribution of surface residues, chemicals, or seeds following tillage operations is of great importance to a wide variety of soil research areas. This paper describes a $1 \mathrm{D}$ empirical vertical soil tillage distribution model with $1 \mathrm{~cm}$ grid spacing (SeedChaser) that predicts vertical redistribution of weed seeds following user selected (a) sequences of tillage implements, and (b) initial seed distribution values. Results of this model are particularly suited for weed seed emergence modeling. However, the model can be adapted easily to any surface broadcasted agrochemical or incorporated residues. The present model can handle up to 20 passes of user selected sequences of 16 different implements. The majority of prior models examined only the impact of a more limited list of implements at much larger depth intervals, which reduced the predictability of fine-scale vertical movement that may be needed for simulating movements of seeds or chemical granules. SeedChaser consolidates the results from these previous models along with new data on conservation tillage implements into a prediction tool that would have applications both in weed science, as well as other soil research areas. SeedChaser was developed in JAVA and is publicly available via the Internet.
\end{abstract}

(C) 2007 Elsevier B.V. All rights reserved.

Keywords: Seed movement; Soil movement; Leslie matrix; Seedbank; Conservation tillage

\section{Introduction}

Vertical weed seed distribution through the soil profile is one of the key factors governing weed emergence. Burial depth directly impacts the ability of seeds to germinate and emerge successfully (Roberts and Feast, 1972), as well as the ability of seeds to avoid predation and decay (Cousens and Mortimer, 1995). To develop an accurate weed emergence model, the distribution of seeds following tillage implement passes is needed. Vertical movement of weed seeds as a consequence of tillage implements has been researched extensively and is the primary cause of alterations in vertical seed distributions (Pareja and Staniforth, 1985; Ball and Miller, 1990; Buhler et al., 1997). Weed seeds can also be moved by rain drop impact, soil organisms, or entry via infiltration through large macropores or cracks (Harris et al., 1966; Sheldon, 1974; Govers et al., 1993, 1996). However, the effects of these factors often are small relative to tillage disturbances (Roberts et al., 1977; Govers et al., 1993, 1996).

Buried seeds occasionally can remain viable in excess of 30 years (Toole and Brown, 1946). Soil tillage stimulates germination of buried seed populations (Chancellor, 1964; Roberts and Potter, 1980), with one potential hypothesis

\footnotetext{
* Corresponding author. Tel.: +1 320589 3411x161; fax: +1 3205893787.

E-mail address: spokas@morris.ars.usda.gov (K. Spokas).
} 
being photo-stimulation of weed seeds (Scopel et al., 1994). However, precise mechanisms still are unknown. Tillage also alters the soil physical structure, which results in different microclimate conditions that impact germination (Stahl et al., 1999). Often only 5\% of the weed seedbank produce seedlings each year (Forcella et al., 1992), indicating that a large seed reservoir within the soil remains subject to various tillage events.

A major gap is the lack of research on weed seed movement following the use of conservation tillage or reduced tillage intensity implements. Even though conservation tillage implements are not as aggressive as traditional implements (e.g., moldboard plow), vertical redistribution of weed seeds still occurs with their use. Reduced tillage intensity practices have been well established in sub-humid and semi-arid regions to reduce soil erosion and conserve soil moisture (Griffith et al., 1986). These practices also are gaining popularity in humid regions to reduce fuel consumption, reduce soil organic carbon losses, and allow producers to farm additional land (Carter, 1994; Derksen et al., 1996). Reduced tillage intensity leads to increased numbers of surface weed seeds due to lack of deep incorporation (Froud-Williams, 1988; Ball and Miller, 1990; Ball, 1992; Yenish et al., 1992). However, the impact of reduced tillage on seed movement within the shallow surface $(0-5 \mathrm{~cm})$ horizon has not been examined rigorously and is critical because shallow depths are more important for weed emergence than deeper depths due to minimal emergence from deeply buried seeds (Roberts and Feast, 1972).

The ability to model the combined effect of tillage implement passes on seeds buried in the shallow surface $(0-5 \mathrm{~cm})$ is paramount to mechanistic models of weed seedling emergence. Prior models have examined 3 or $5 \mathrm{~cm}$ depth intervals for seed distributions (e.g., Moss, 1988; Cousens and Moss, 1990; Pawlowski and Malicki, 1968). However, these intervals are too large for the fine scale required in detailed seed germination models. To date, these shallower intervals have been extrapolated by curve fitting or linear approximation (e.g., Mohler et al., 2006). In addition, fast Fourier transforms (Mead et al., 2003; Brain and Marshall, 1999) and probability density functions (Marshall and Brain, 1999) have been utilized to model seed movement as well. These mathematical extrapolations are only valid if the behavior is similar among the depths.

The purpose of this paper is to provide detailed data on conservation tillage implements, in addition to traditional implements, and to develop a fine-scale soil tracking model for seed and soil particle movement using depth increments $(1 \mathrm{~cm})$ smaller than those used in prior models. The simulations resulting from this model are not limited just to weed seed research, but may be relevant to distributions and redistributions of many management entities, such as broadcast fertilizers, pesticide granules, fumigants, and crop residues.

\section{Materials and methods}

Field experiments were conducted at the Swan Lake Research Farm in west central Minnesota, USA (45.7N, 95.8W). The soil is a silty clay loam of the Barnes series (fine-loamy, mixed, frigid Calcic Hapludoll) with a surface $(0-10 \mathrm{~cm})$ pre-tillage bulk density of $1.4 \pm 0.3 \mathrm{~g} \mathrm{~cm}^{-3}$ and volumetric water content of $0.31 \pm 0.10 \mathrm{~m}^{3} \mathrm{H}_{2} \mathrm{O} \mathrm{m}^{-3}$ soil during field experiments. Experiments were performed during spring through autumn over the course of 2 years. Consequently, soil conditions varied across experiments but always were within the accepted range of standard farming practices.

Before each pass of the implements studied (see below), plastic beads were buried manually in the soil to overcome the difficulties of mechanized bead plantings. Use of plastic and ceramic beads has been substantiated in prior experiments for tracking soil movement due to tillage (e.g., Moss, 1988; Cousens and Moss, 1990; Straicka et al., 1990; Staricka et al., 1991). Seed burial locations were established as an $8 \mathrm{~cm}$ diameter hole created with a soil bucket auger to a total depth of $25 \mathrm{~cm}$. A piece of plywood $(1 \mathrm{~m} \times 0.5 \mathrm{~m} \times 1.5 \mathrm{~cm})$ was used to establish a reference surface level. Twelve unique plastic bead colors were buried at $1 \mathrm{~cm}$ intervals to $12 \mathrm{~cm}$, and then at 15,17 and $20 \mathrm{~cm}$. Beads were also buried at $25 \mathrm{~cm}$ (below the depth of tillage) to verify original soil surface level. Thirty beads (corresponding bead density of approximately 6000 beads $\mathrm{m}^{-2}$ ) were buried carefully at each depth. Each bead was $6 \mathrm{~mm}$ in diameter with a density of $1090 \mathrm{~kg} \mathrm{~m}^{-3}$. Initial experiments were conducted to confirm that bead size ( 3 or $6 \mathrm{~mm}$ ) did not alter post-tillage profiles. There were no statistically significant differences observed between the bead sizes (Fig. 1). This finding is in agreement with Soriano et al. (1968) who observed no differences in the distribution of seeds in two plant species after tillage even though the seeds were different sizes. Larger plastic beads $(6 \mathrm{~mm})$ were subsequently used to ease field retrieval.

Bead depths were confirmed manually using a ruler during the burial with three measurements taken around the interior of the auger hole after each layer of beads was placed. The plywood reference expedited these measurements. Each bead layer was sequentially buried with the correct mass of soil to complete a $1 \mathrm{~cm}$ lift $(86.5 \mathrm{~g}$ field moist soil) and then soil was tamped to achieve original bulk density $\left(1.4 \mathrm{~g} \mathrm{~cm}^{-3}\right)$, which was confirmed again by manual depth measurement. This process was continued until all bead colors were buried. Typically, 5-10 replicates were 

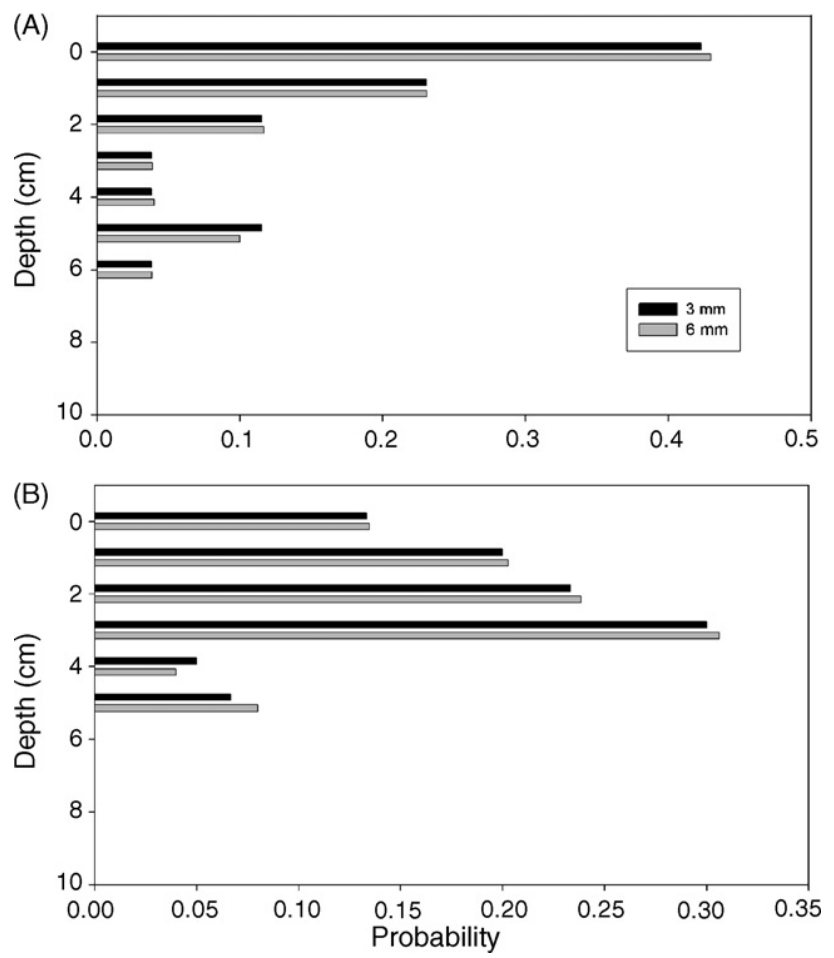

Fig. 1. Resulting distribution pattern for 3 and $6 \mathrm{~mm}$ plastic beads placed (A) on the soil surface and (B) at $3 \mathrm{~cm}$ following the passage of a field cultivator. Back-transformed means of five replicates are shown for the probabilities of finding the bead at that respective depth. No significant differences were noted between the bead diameters for either depth (paired $t$-test on back-transformed means; $p>0.10$ ).

conducted for each tillage implement, with one bead burial per implement pass to avoid cross-contamination between bead columns.

For most implements that were tested, columns of beads were placed randomly in the intended path of the implement. However, for the residue management and strip-tillage implements, beads were buried only in the crop row where soil disturbance occurred, and for the inter-row cultivator beads were buried only in the inter-row spacing.

A variety of methods have been used to document plastic and ceramic bead travel in soil. There are mainly two groupings: statistically based soil core sampling (e.g., Roberts and Ricketts, 1979; Grundy et al., 1999) and field soil excavation (e.g., Mohler et al., 2006). For this study, a modified excavation strategy was deployed. Soil was excavated carefully in situ without the aid of a box frame as in Mohler et al. (2006). In this manner the exact placement of each bead could be recorded, including both horizontal and vertical translocation. Beads found on the surface after tillage were initially flagged (Fig. 2A). Then soil was cautiously excavated in $1 \mathrm{~cm}$ increments to $25 \mathrm{~cm}$ depth in the area outlined by these flags by careful scraping with a hand trowel. Color as well as the horizontal and vertical position of each bead was recorded as the beads were encountered during the excavation (Fig. 2B). Excavation was initiated by digging a hole and then progressing horizontally, vertically scraping the soil from the surface to $25 \mathrm{~cm}$ in $1 \mathrm{~cm}$ increments. This was a labor intensive process, but ensured both high recovery rates of the buried beads $(>90 \%)$ and accurate accounting of soil movement and corresponding weed seed translocation resulting from tillage implements.

\subsection{Implements}

Ten tillage implements were examined in this work and are summarized in Table 1 and Fig. 3. The residue management (RM) and strip-tillage (ST) implements were customized implements (Reicosky, 1998). The RM implement was a customized Yetter ${ }^{1}$ L128 fertilizer row unit (without the fertilizer knifes). The tillage implement consisted of

\footnotetext{
${ }^{1}$ Names are necessary to report factually on available data; however, the USDA neither guarantees nor warrants the standard of the product, and the use of the name by USDA implies no approval of the product to the exclusion of others that may also be suitable.
} 


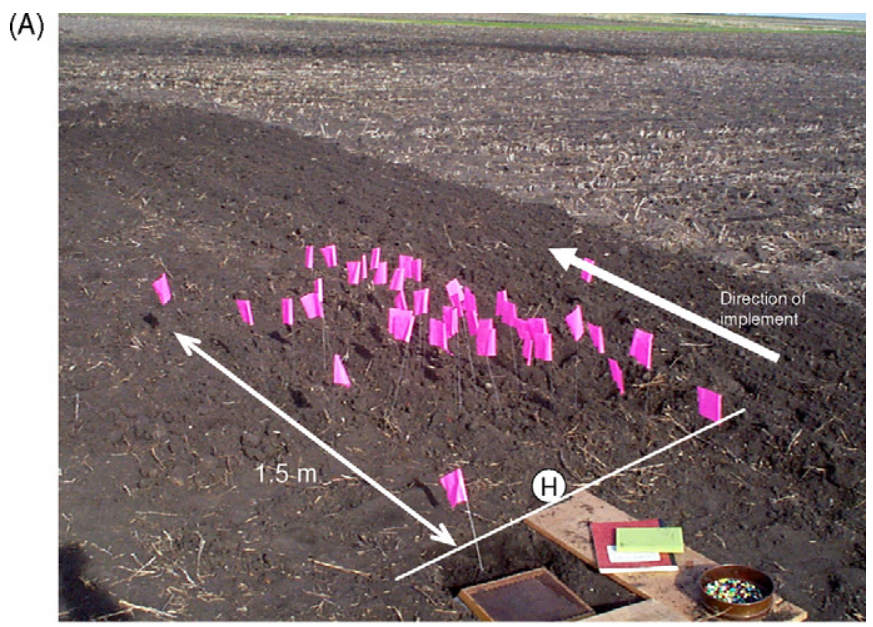

(B)

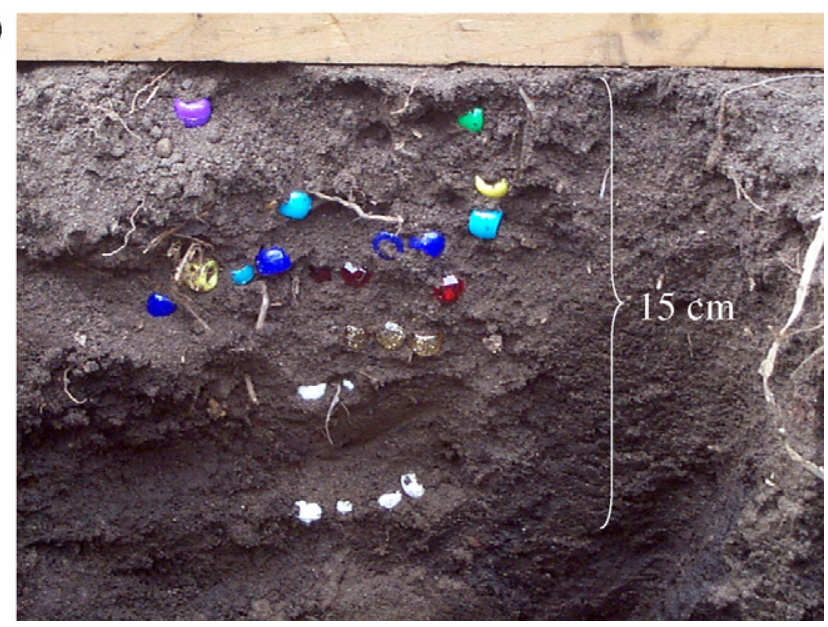

Fig. 2. Illustrations of the recovery process of beads following the field cultivator are shown. (A) Bead's original position was at the location marked with a " $\mathrm{H}$ " and the maximum horizontal movement recorded was $1.5 \mathrm{~m}$, the majority (>80\%) of the beads moved less than $1 \mathrm{~m}$. (B) Illustrates the distribution of beads following tillage in the soil during excavation recovery.

four tillage tools one tool for each row (four rows spaced $76 \mathrm{~cm}$ apart) with a 13-wave coulter that penetrated $8 \mathrm{~cm}$ and residue managers (spoke wheels set on an angle) that moved the surface residue away from the row-center and loosened the soil surface $5 \mathrm{~cm}$ deep and about $10 \mathrm{~cm}$ wide (Fig. 3E). The ST tool was the same as the RM implement, except four Mole Knifes (Hi-Pro Mfg.) also were attached to each row and each knife had a $1 \mathrm{~cm}$ wide shank that loosened the soil to $15 \mathrm{~cm}$ deep (Reicosky, 1998). Remaining implements were not customized and details are given in Table 1. Each implement was operated at typical field speed $\left(\approx 7 \mathrm{~km} \mathrm{~h}^{-1}\right)$ and sufficient tillage distance $(\approx 20 \mathrm{~m})$ was allowed before the seed burial points to allow the implement to achieve stable operating speed. Juzwik et al. (1997) noted that there were no observable differences in the distribution of ceramic spheres placed on the surface for spading machines up to speeds of $3 \mathrm{~km} \mathrm{~h}^{-1}$. Experiments on the impact of implement speed were not conducted in this study.

\subsection{Statistical analyses}

Probability values were calculated based on the number of beads recovered at the particular depth interval divided by the total number of beads originally at the starting depth. Since probabilities are limited numerically to values between 0 and 1, several transformations have been applied to percent and probability data: the logarithmic (natural or base 10) transform, arcsine transform, and square-root transform (Sokal and Rohlf, 1981). Arcsine transformation was used in this study, but results are reported as back-transformed means. 
Table 1

Outline of sources of the translation matrices for each implement used in the SeedChaser model

\begin{tabular}{lllll}
\hline Implement & Figure & Working depth $(\mathrm{cm})$ & Extrapolated & Source of data \\
\hline Paraplow (Howard) & 3A & 25 & & This study \\
Moldboard plow (Case 500) & 3B & 24 & & This study \\
Field cultivator (WilRich 2500) & 3C & 12 & & This study \\
Disc (John Deere 115) & 3D & 11 & & This study \\
Chisel plow (John Deere 610) & 3E & 23 & & This study \\
Row cultivator (John Deere 886) & 3F & 13 & & This study \\
Rotary hoe (John Deere 400) & 3G & 7 & & This study \\
Drill (John Deere 9350) & 3H & 9 & & This study \\
Strip till (Custom-see text) & 3I & 12 & & This study \\
Residue manager (Custom-see text) & 3I & 7 & $\sqrt{ }$ & Mead et al. (1998) \\
Spring tine & & & Mead et al. (1998) \\
Power harrow & & & Mead et al. (1998) \\
Rotovator & & & Mead et al. (1998) \\
Spader (spading machine) & & $\sqrt{ }$ & Cousens and Moss (1990) \\
Moldboard plow (with skim-coulter) & & $\sqrt{ }$ & Cousens and Moss (1990) \\
Rigid tine & & & Rahman et al. (2000) \\
Rotary hoe & & & Pekrun et al. (2005) extended the \\
Disc & & & & spring tine matrix of Cousens and \\
& & & & Moss (1990) over 10 cm for disc \\
\hline
\end{tabular}

Note: Manufacture and model are given as a reference.

(A)

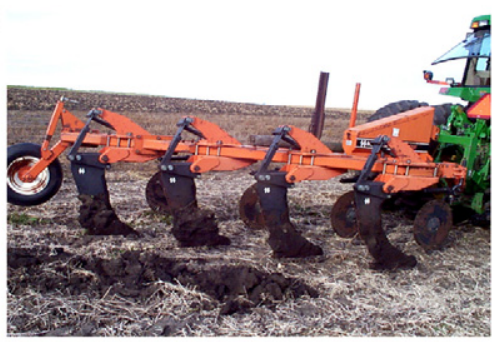

(D)

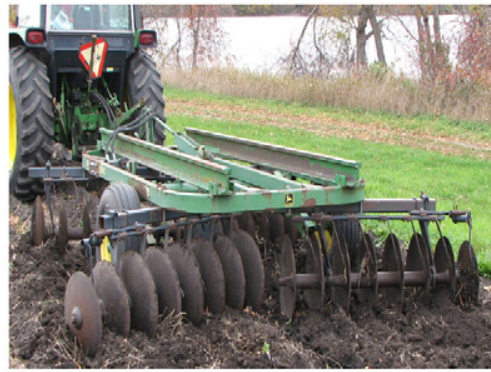

(G)

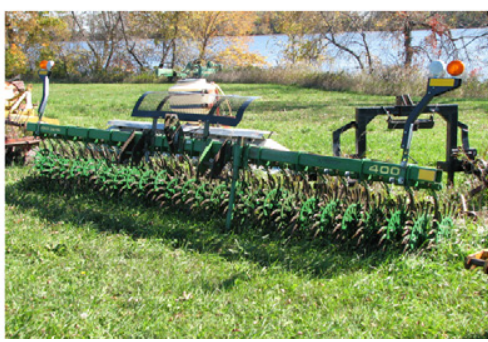

(B)

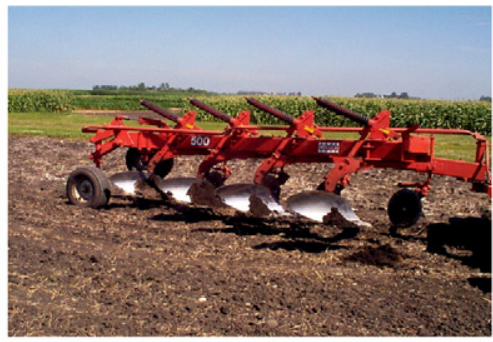

(E)

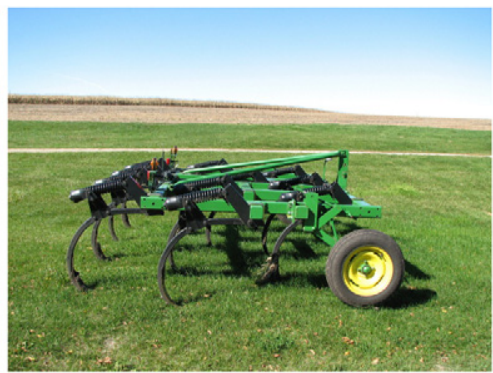

(H)

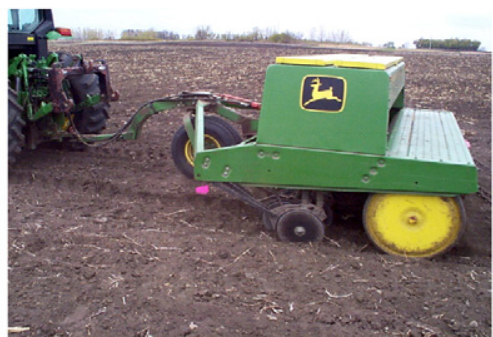

(C)

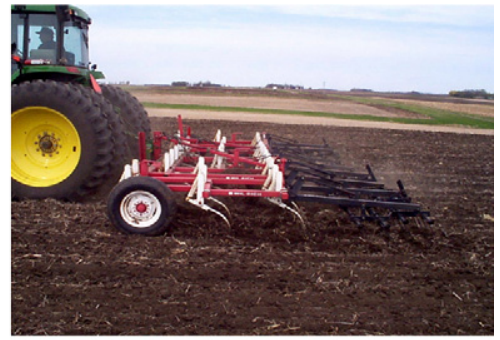

(F)

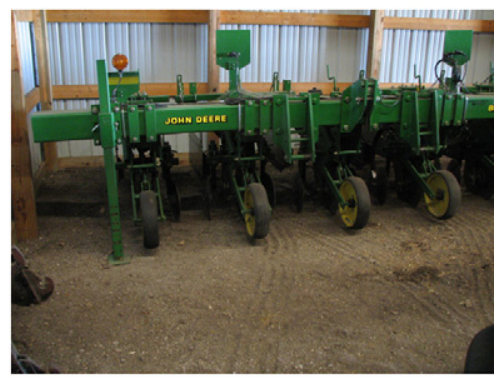

(I)

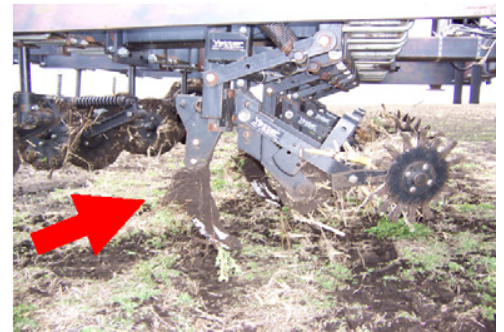

Fig. 3. Photographs of the tillage implements used in this study: (A) paraplow, (B) moldboard plow, (C) field cultivator, (D) disc, (E) chisel plow, (F) row cultivator, $(\mathrm{G})$ rotary hoe, $(\mathrm{H})$ drill, and (I) customized strip tillage (ST)/residue management (RM) implement. The ST implement is shown in (I), whereas the residue management implement was the same except the Mole Knife (shown with arrow in Fig. 1) was removed. 
Field validations were compared to the model output through the use of three assessments: correlation coefficient $(r)$, modeling index $(d)$, and modeling efficiency (ME). Modeling index $(d)$ was calculated with the following expression:

$$
d=1-\left[\frac{\sum_{i=1}^{n}\left(x_{i}-y_{i}\right)^{2}}{\sum_{i=1}^{n}\left(\left|x_{i}-\bar{x}_{i}\right|\right)+\left(\left|y_{i}-\bar{x}_{i}\right|\right)^{2}}\right],
$$

where $x_{i}$ is the observed number of beads at depth $i$ with a mean of $\bar{x}_{i}$ and $y_{i}$ is the modeled probability values at that particular depth (Willmott, 1981; Mayer and Butler, 1993). The value of $d$ will vary between 0 and 1 , with a value of 1 indicating perfect model agreement (Willmott, 1981).

Modeling efficiency (ME) was calculated by the following formula:

$$
\mathrm{ME}=1-\left[\frac{\sum_{i=1}^{n}\left(x_{i}-y_{i}\right)^{2}}{\sum_{i=1}^{n}\left(x_{i}-\bar{x}_{i}\right)^{2}}\right],
$$

where $x_{i}$ are the measured beads recovered at depth $i$ with a mean of $\bar{x}_{i}$, and $y_{i}$ are the corresponding modeled values (Mayer and Butler, 1993; Legates and McCabe, 1999). ME will vary between minus $-\infty$ and 1 with higher values (closer to 1) indicative of superior model performance (Willmott, 1982). Comparisons were performed for total beads at each depth recovered in the field versus results from the model of initial bead distribution.

\section{Model development}

The main framework adapted in this model is the Leslie matrix (Cousens and Moss, 1990; Gonzalez-Andujar, 1997; Mead et al., 1998). This model currently accounts solely for vertical displacement. The transition matrix describes the probability of the vertical movement (bidirectional) of seeds moving from one layer to another layer. Maximum depth modeled currently is $18 \mathrm{~cm}$. Multiplying this probability matrix by the seed distribution prior to the implement pass, results in the prediction of the seed distribution following each implement pass:

$$
\left[\begin{array}{c}
n_{0 \mathrm{~cm}, \text { till }} \\
n_{1 \mathrm{~cm}, \text { till }} \\
n_{2 \mathrm{~cm}, \text { till }} \\
\vdots \\
n_{18 \mathrm{~cm}, \mathrm{till}}
\end{array}\right]=\left[\begin{array}{cccc}
P_{0 \mathrm{~cm}, 0 \mathrm{~cm}} & P_{1 \mathrm{~cm}, 0 \mathrm{~cm}} & \cdots & P_{18 \mathrm{~cm}, 0 \mathrm{~cm}} \\
P_{0 \mathrm{~cm}, 1 \mathrm{~cm}} & P_{1 \mathrm{~cm}, 1 \mathrm{~cm}} & \cdots & P_{18 \mathrm{~cm}, 1 \mathrm{~cm}} \\
P_{0 \mathrm{~cm}, 2 \mathrm{~cm}} & P_{1 \mathrm{~cm}, 2 \mathrm{~cm}} & \cdots & P_{18 \mathrm{~cm}, 2 \mathrm{~cm}} \\
\vdots & \vdots & & \vdots \\
P_{0 \mathrm{~cm}, 18 \mathrm{~cm}} & P_{1 \mathrm{~cm}, 18 \mathrm{~cm}} & \cdots & P_{18 \mathrm{~cm}, 18 \mathrm{~cm}}
\end{array}\right]\left[\begin{array}{c}
n_{0 \mathrm{~cm}, \mathrm{start}} \\
n_{1 \mathrm{~cm}, \mathrm{start}} \\
n_{2 \mathrm{~cm}, \mathrm{start}} \\
\vdots \\
n_{18 \mathrm{~cm}, \mathrm{start}}
\end{array}\right]
$$

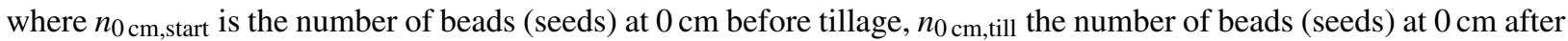
tillage, and $P_{0 \mathrm{~cm}, 1 \mathrm{~cm}}$ is the probability of a bead moving from 0 to $1 \mathrm{~cm}$.

Three randomly selected replicates were used as the model development data set, with the remaining replicates constituting model validation sets. Replicates from model development data sets for each tillage implement were summed based on color for the recovered depth $(j)$ and then divided by the total number of beads buried at the original depth $(i)$ to calculate the probability of a bead moving from layer $i$ to $j$ (Grundy et al., 1999; Mead et al., 1998; Cousens and Moss, 1990). Since replicates were conducted at different soil water contents and different seasons, the probability matrices developed present average movement probabilities of the particular tillage implement. Our goal was to capture the average movement due to the tillage implement and not focus on differences that occur within the field. This was the main reason for having replicates of each implement conducted at different soil conditions to account for this variability. Attempts were made to sample outside of the standard moisture range, but dry soil hampered field excavation method (due to collapsing of the excavation pit) and wet soil provided random distribution patterns that were not replicable (data not shown). All the transition matrices for the 10 tillage implements studied are included in the supplemental information (Tables S1-S10).

To create a more robust model, data were located in the literature (Table 1) for other implements to supplement the number of implements included in the model. Tillage matrices typically given in the literature were for a selected depth range (e.g., $0-5 \mathrm{~cm}, 5-10 \mathrm{~cm}$, etc.). This is a practical depth range for some purposes, but a more 

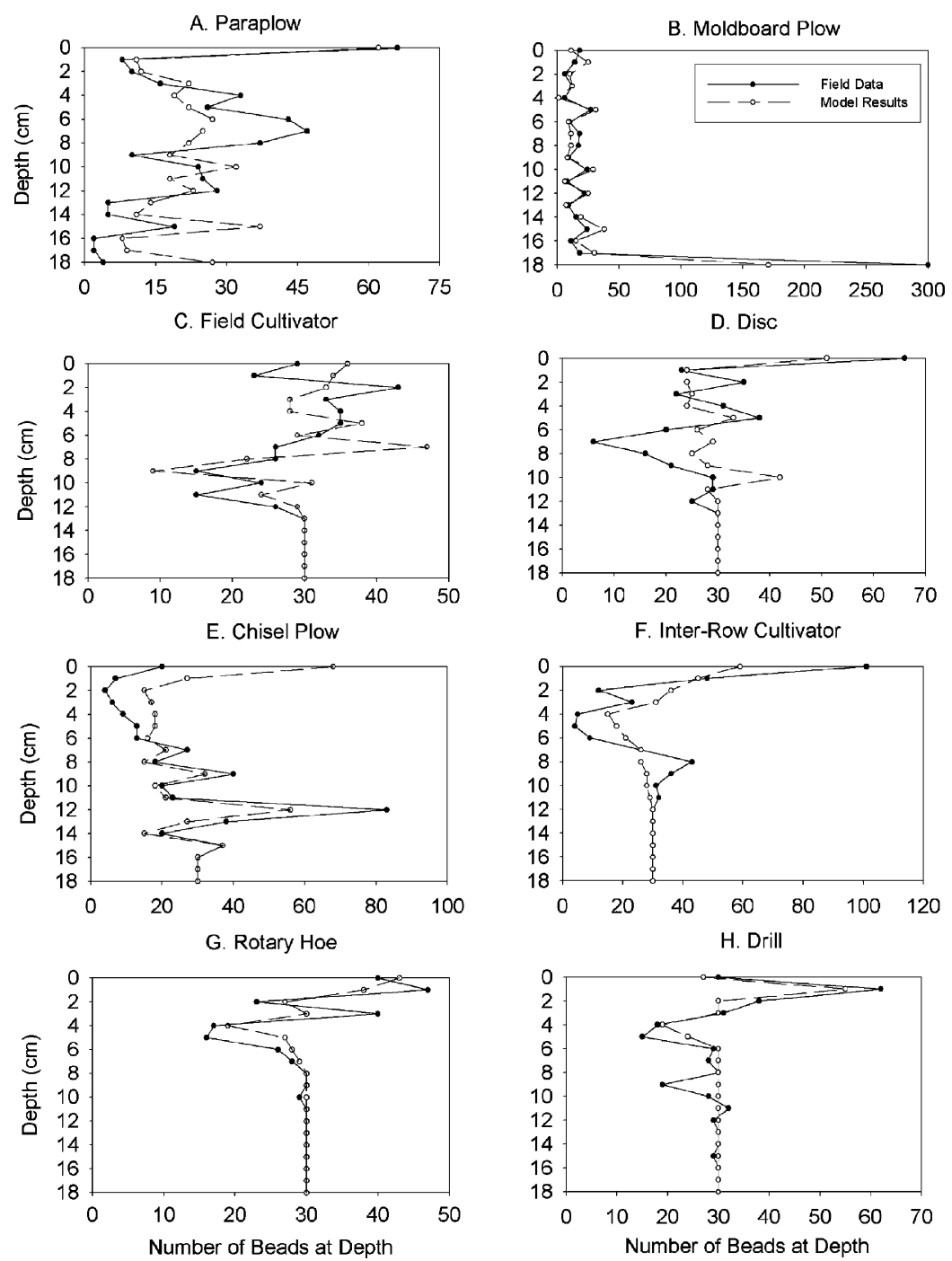

Fig. 4. Comparison of measured distribution patterns for 30 beads initially buried at each $1 \mathrm{~cm}$ interval from 0 to $18 \mathrm{~cm}$ following tillage compared to the results from SeedChaser for (A) paraplow, (B) moldboard plow, (C) field cultivator, (D) disc, (E) chisel plow, (F) row cultivator, (G) rotary hoe, and $(\mathrm{H})$ drill.

detailed prediction seed depth is needed for successful microclimate modeling of weed seed germination. Commonly, probability distributions are fit to distribution functions to extrapolate intermediate depths that were not measured directly (e.g., Mohler et al., 2006). However, data collected in this experiment indicated that there are narrow and implement-specific "critical" depths where seeds amass or diminish unlike that occurring at surrounding depths (e.g., Fig. 4E and F). Therefore, the extrapolation of the results from widely sampled intervals (e.g., $0-5 \mathrm{~cm})$ to arrive at smaller sample distributions must be performed with caution. We included these extrapolated implement matrices to make the model more universal. Tillage implements that were extrapolated are listed in Table 1.

These matrix calculations were coded in the Java programming language within a newly created computer application (SeedChaser). SeedChaser predicts the movement of weed seeds (or any other particle or granule) following a user selectable sequence of tillage events. Currently, the model accommodates up to 20 tillage passes of any of the 16 current implements included in the model. Resulting output is displayed numerically and graphically, and can also be saved to a file for subsequent analysis. 
Table 2

Statistical measures of validation for the SeedChaser model vs. field observations (all beads and depths) for all tillage implements measured

\begin{tabular}{|c|c|c|c|c|}
\hline Implement & Replicate & $r$ & $d$ & $\mathrm{ME}$ \\
\hline \multirow[t]{3}{*}{ Paraplow } & 1 & 0.854 & 0.902 & 0.705 \\
\hline & 2 & 0.748 & 0.862 & 0.603 \\
\hline & 3 & 0.777 & 0.861 & 0.603 \\
\hline \multirow[t]{4}{*}{ Moldboard plow } & 1 & 0.978 & 0.908 & 0.777 \\
\hline & 2 & 0.996 & 0.966 & 0.800 \\
\hline & 3 & 0.962 & 0.852 & 0.682 \\
\hline & 4 & 0.990 & 0.988 & 0.958 \\
\hline \multirow[t]{3}{*}{ Field cultivator } & 1 & 0.902 & 0.945 & 0.775 \\
\hline & 2 & 0.791 & 0.820 & 0.246 \\
\hline & 3 & 0.735 & 0.841 & 0.529 \\
\hline \multirow[t]{3}{*}{ Disc } & 1 & 0.886 & 0.920 & 0.767 \\
\hline & 2 & 0.971 & 0.935 & 0.780 \\
\hline & 3 & 0.855 & 0.932 & 0.704 \\
\hline \multirow[t]{3}{*}{ Chisel plow } & 1 & 0.603 & 0.760 & 0.071 \\
\hline & 2 & 0.757 & 0.835 & 0.561 \\
\hline & 3 & 0.722 & 0.834 & 0.480 \\
\hline \multirow[t]{3}{*}{ Inter-row cultivator } & 1 & 0.868 & 0.891 & 0.711 \\
\hline & 2 & 0.871 & 0.925 & 0.758 \\
\hline & 3 & 0.826 & 0.842 & 0.622 \\
\hline \multirow[t]{3}{*}{ Rotary hoe } & 1 & 0.964 & 0.982 & 0.929 \\
\hline & 2 & 0.973 & 0.986 & 0.943 \\
\hline & 3 & 0.976 & 0.987 & 0.946 \\
\hline \multirow[t]{2}{*}{ Drill } & 1 & 0.962 & 0.983 & 0.936 \\
\hline & 2 & 0.707 & 0.845 & 0.550 \\
\hline \multirow[t]{3}{*}{ Residue manager (RM) } & 1 & 0.836 & 0.879 & 0.670 \\
\hline & 2 & 0.743 & 0.874 & 0.434 \\
\hline & 3 & 0.877 & 0.936 & 0.734 \\
\hline \multirow[t]{3}{*}{ Strip tillage (ST) } & 1 & 0.934 & 0.964 & 0.875 \\
\hline & 2 & 0.944 & 0.973 & 0.898 \\
\hline & 3 & 0.907 & 0.949 & 0.794 \\
\hline
\end{tabular}

Notes: $r$ is the Pearson's correlation, $d$ is the modeling index, and ME is the model efficiency. These statistical measures are defined in Section 2.2 .

\section{Discussion}

SeedChaser was validated against remaining field replicates that were not used for the original model development (Table 2). All of the tillage implements were successfully modeled with all three statistical parameters indicating good model agreement for total bead movement. As seen in Table 2, $d$ ranged from 0.76 to 0.99 , ME ranged from 0.07 to 0.96 , and $r$ ranged from 0.60 to 0.996 , indicating good model predictability. Moldboard plow, chisel plow, and paraplow implements disturbed beads (seeds) below $10 \mathrm{~cm}$ (Fig. 4), whereas the field cultivator, disc, row cultivator, rotary hoe, and drill only disturbed shallow beads (seeds). Fig. 4 assumed that there were 30 beads at each of the starting depths and compared results from SeedChaser and collected field data for total beads at each depth.

The chisel plow had the lowest overall statistical fits (Table 2). This most likely was due to the probability of buried beads being hit squarely by a chisel shear or potentially being glanced by the side of a chisel shear. However, despite this potential issue the model still performed adequately in predicting the bead movements in the soil following chisel plowing.

Interpolated matrices for the rotary hoe and moldboard plow were compared to the field data collected in this experiment (Fig. 5). Statistically, the interpolated matrices did not perform as well as the more detailed matrices developed in this current work (Table 3). Correlation ranged from 0.24 to $0.62, d$ was between 0.11 and 0.77 , and ME ranged from 0.03 to 0.33 . Despite these measures being lower for the interpolated matrices, generally the interpolated 

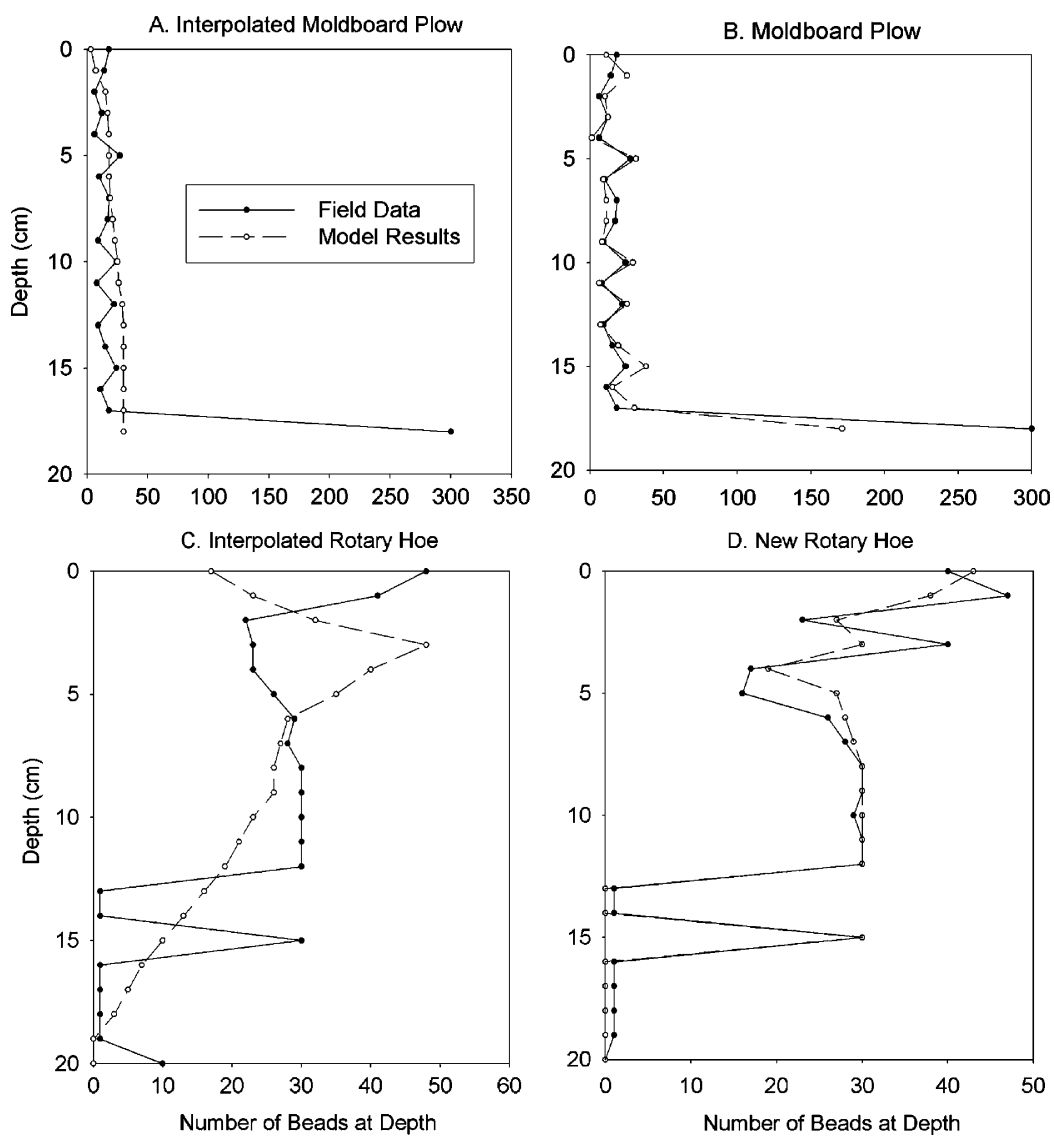

Fig. 5. Comparison of the literature interpolated matrices vs. the field observations for the moldboard plow and the rotary hoe implements.

matrices still predicted the overall shape of the distribution (Fig. 5). These results show the importance of more precise measurements to more accurately predict weed seed distribution as imposed by tillage implements, particularly near the surface.

Distribution curves were not necessarily smooth curves. Fig. 4E illustrates the depth of $12 \mathrm{~cm}$ being a "critical depth" for the chisel plow. This depth accumulated the highest number of beads ( $85 \pm 10$ beads for all replicates). We feel this is due to the trench opening effect of the curved chisel blades and the beads were able to fall to the base of this trench. This is one example of the critical depth phenomenon that might not be captured by averaging coarser depth intervals (e.g., Mohler et al., 2006). Even though this depth accumulated the most seeds, surface seeds were distributed predominately between 0 and $6 \mathrm{~cm}$ with the chisel plow, which is in agreement with the results from Straicka et al.

Table 3

Statistical measures of validation for the interpolated matrices from literature sources within the SeedChaser model vs. field measured replicates from the current study (all beads and depths)

\begin{tabular}{lllll}
\hline Implement & Replicate & $r$ & $d$ & ME \\
\hline Moldboard plow & 1 & 0.246 & 0.130 & 0.295 \\
& 2 & 0.280 & 0.108 & 0.030 \\
& 3 & 0.269 & 0.120 & 0.038 \\
Rotary hoe & 4 & 0.275 & 0.774 & 0.044 \\
& 1 & 0.615 & 0.714 & 0.143 \\
& 2 & 0.516 & 0.714 & 0.161
\end{tabular}

Notes: $r$ is the Pearson's correlation, $d$ is the modeling index, and ME is the model efficiency. These statistical measures are defined in Section 2.2 . 


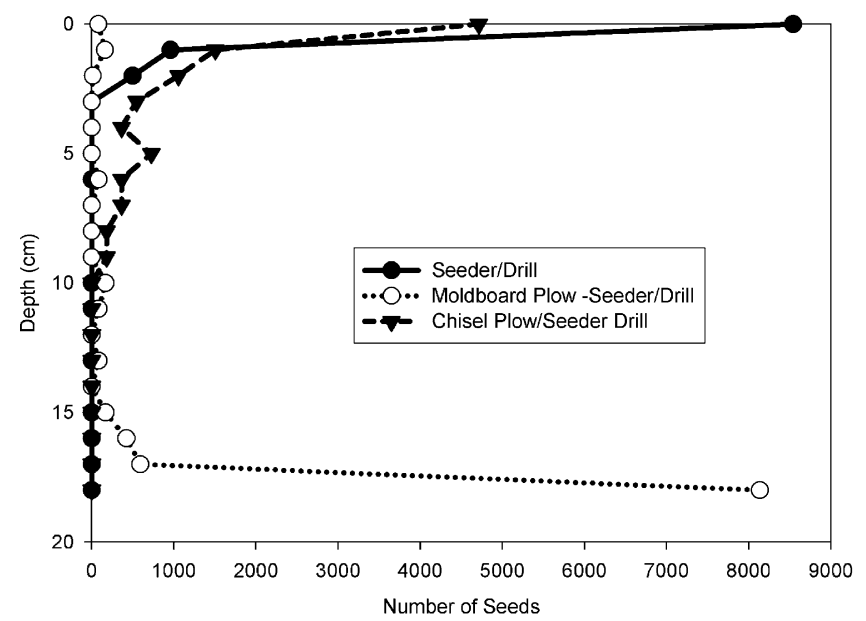

Fig. 6. Comparison of SeedChaser simulation of a drill (no-till) versus a combination of a moldboard or chisel plow followed by a drill on the overall seed distributions originally assuming there were 10,000 seeds at the surface.

(1990). Another example is with the drill (Fig. 4H). With this implement, the $1 \mathrm{~cm}$ depth accumulated the highest number of beads from beads falling from the surface as well as some beads being brought from $2 \mathrm{~cm}$ depth to $1 \mathrm{~cm}$. If the detailed depth intervals of $1 \mathrm{~cm}$ were not used, this movement would have been missed, particularly if the original sowing depths of beads were 0 and $5 \mathrm{~cm}$. This near surface movement is particularly critical for no-till situations were the majority of weed seeds remain on the surface following dispersal in the fall. This disruption by a drill would be enough to provide a mechanism for a high proportion of surface seeds to be buried at the $1 \mathrm{~cm}$ depth. More weed seeds would appear in the surface $1 \mathrm{~cm}$ depth from a drill passing over a no-till field versus a drill following moldboard or chisel plowing (Fig. 6), assuming equal initial starting surface seed distributions. Small differences in seed burial depth result in large differences in seedling recruitment, even for large-seeded weeds like wild oat (Avena fatua L.). In no-till wheat, for example, the ranges for depths for the 25th and 75th percentiles of seedling recruitment are $0.4-0.7$ and $1.8-2.0 \mathrm{~cm}$, respectively (Chauan et al., 2006). Thus, errors of simulated seed burial depths of only $1 \mathrm{~cm}$ potentially could create much larger errors for predictions of seedling recruitment.

In order to further validate the SeedChaser model, additional experimental results were taken from available literature. SeedChaser was verified using the results of Rahman et al. (2000) for the vertical seed distribution following power harrowing. Initial seed distribution for an undisturbed soil (see Fig. 1a in Rahman et al. (2000)) was used to set the initial seed distribution before tillage in SeedChaser. As indicated in the study of Rahman et al. (2000), power harrowing did not significantly redistribute the vertical profile of seeds. This was confirmed by the developed model, and it accurately predicted the vertical distribution of seeds $(r=0.988 ; d=0.991 ; \mathrm{ME}=0.969)$. Data also were used from Rahman et al. (2000) to validate the rotary hoe matrix, and again SeedChaser performed well $(r=0.990 ; d=0.995 ; \mathrm{ME}=0.981)$. Lastly, the interpolated spading machine matrix was validated against the data found in Juzwik et al. (1997) for the vertical distribution of surface applied granules following a spading machine. Initial seed distribution was solely on the surface. SeedChaser again predicted the resulting vertical profile with very good accuracy $(r=0.990 ; d=0.991$; $\mathrm{ME}=0.968$ ). This validation illustrates the potential use of SeedChaser for modeling surface applied agrochemical incorporation.

Differences among soil types have been ignored in SeedChaser. The developed model is viewed as a tool for common agricultural soils (i.e., loam soil). Cardina et al. (1991) showed that the distribution patterns after various tillage operations for two silt loam soils were nearly identical but differed from those within a silty clay loam soil. In addition, Swanton et al. (2000) observed that tillage distribution is different in sandy soil versus finer texture soils. Whether these differences were due to soil type or other management factors (e.g., autumn tillage for silt loam versus spring tillage for silty clay loam or soil water content differences) remain unknown. Whatever the case, further research is needed on the effect of soil type for resulting seed distributions before a soil type input component can be added to SeedChaser. 


\section{Conclusions}

The SeedChaser model was the first to use 1-cm spacing field measurements to characterize movement of weed seeds in soil as a consequence of tillage. Other studies used extrapolation techniques to arrive at finer intervals. Research topics other than weed seeds for which SeedChaser results may be relevant include movement and distribution of granules of fertilizers, insecticides, and herbicides; fumigants; and crop residues. Although results from SeedChaser are suited particularly well for weed seedling emergence modeling, it can be adapted easily to any surface broadcasted, incorporated, or injected agrochemical. SeedChaser can handle up to 20 passes with a user selected sequence of 16 different implements. The model consolidates the results from previous literature models along with new data on conservation tillage and planting implements into a prediction tool that has applications in weed science as well as soil research and management. This model was developed in JAVA, is simple to use, and is publicly available via the Internet (http://www.ars.usda.gov/mwa/ncscrl—located in Products and Services). SeedChaser is seen as a perpetually developing product. As additional implements are studied, these can be added easily to the model.

\section{Acknowledgments}

The authors would like to express their gratitude to Dean Peterson, Chuck Hennen, Scott Larson, Seth Miller, and Chris Wente for their assistance with the field work and to Andrew Kuhn and Andy Korth for Java programming assistance. This work was supported by USDA-CSREES-NRI agreement number 2005-35320-15400.

\section{Appendix A. Supplementary data}

Supplementary data associated with this article can be found, in the online version, at doi:10.1016/j.compag.2007.01.014.

\section{References}

Ball, D.A., 1992. Weed seedbank response to tillage, herbicides, and crop rotation sequences. Weed Sci. 40, 654-659.

Ball, D.A., Miller, S.D., 1990. Weed seed population response to tillage and herbicide use in three irrigated cropping sequences. Weed Sci. 38, 511-517.

Brain, P., Marshall, E.J.P., 1999. Modeling cultivation effects using fast Fourier transforms. J. Agric. Biol. Environ. Stat. 4, $276-289$.

Buhler, D.D., Hartzler, R.G., Forcella, F., 1997. Implications of weed seedbank dynamics to weed management. Weed Sci. 45, 329-336.

Cardina, J., Regnier, E., Harrison, K., 1991. Long-term tillage effects on seed banks in three Ohio soils. Weed Sci. 39, $186-194$.

Carter, M.R., 1994. A review of conservation tillage strategies for humid temperate regions. Soil Tillage Res. 31, $289-301$.

Chancellor, R.J., 1964. Emergence of weed seedlings in the field and the effects of different frequencies of cultivation. In: Proceeding of the Seventh British Weed Control Conference, pp. 599-606.

Chauan, B.S., Gill, G., Preston, C., 2006. Seedling recruitment pattern and depth of recruitment of 10 weed species in minimum tillage and no-till seeding systems. Weed Sci. 54, 658-668.

Cousens, R., Mortimer, M., 1995. Dynamics of Weed Population. Cambridge University Press, Cambridge, pp. 88-111.

Cousens, R., Moss, S.R., 1990. A model for the effects of cultivation on the vertical distribution of weed seeds within the soil. Weed Res. 30, 61-70.

Derksen, D.A., Blackshaw, R.E., Boyetchko, S.M., 1996. Sustainability, conservation-tillage and weeds in Canada. Can. J. Plant Sci. 76, 651-659.

Forcella, F., Wilson, R.G., Renner, K.A., Dekker, J., Harvey, R.G., Alm, D.A., Buhler, D.D., Cardina, J., 1992. Weed seedbanks of the US corn belt: magnitude, variation, emergence and application. Weed Sci. 40, 636-644.

Froud-Williams, R.J., 1988. Changes in weed flora with different tillage and agronomic management systems. In: Altieri, M.A., Liebman, M. (Eds.), Weed Management in Agroecosystems: Ecological Approaches. CRC Press, Boca Raton, FL, USA, pp. 213-236.

Gonzalez-Andujar, J.L., 1997. A matrix model for the population dynamics and vertical distribution of weed seedbanks. Ecol. Model. 97, 117-120.

Govers, G., Quine, T.A., Walling, D.E., 1993. The effects of water erosion and tillage movement on hillslope profile development: a comparison of field observations and model results. In: Wicherek, S. (Ed.), Farm Land Erosion in Temperate Plains and Hills. Elsevier, Amsterdam, pp. 285-300.

Govers, G., Quine, T.A., Desmet, P.J.J., Walling, D.E., 1996. The relative contribution of soil tillage and overland flow erosion to soil redistribution on agricultural land. Earth Surf. Process. Landforms 21, 929-946.

Griffith, D.R., Mannering, J.V., Box, J.E., 1986. Soil and moisture management with reduced tillage. In: Sprague, M.A., Triplett, G.B. (Eds.), No-tillage and Surface Tillage Agriculture. John Wiley \& Sons, New York, USA, pp. 19-57.

Grundy, A.C., Mead, A., Burston, S., 1999. Modeling the effect of cultivation on seed movement with application to the prediction of weed seedling emergence. J. Appl. Ecol. 36, 663-678.

Harris, R.F., Chesters, G., Allen, O.N., 1966. Dynamics of soil aggregation. Adv. Agron. 18, 107-169. 
Juzwik, J., Stenlund, D.L., Allmaras, R.R., Copeland, S.M., McRoberts, R.E., 1997. Incorporation of tracers and dazomet by rotary tillers and a spading machine. Soil Tillage Res. 41, 237-248.

Legates, D.R., McCabe, G.J., 1999. Evaluating the use of "goodness-of-fit" measures in hydrologic and hydroclimatic model validation. Water Resour. Res. 35, 233-241.

Marshall, E.J.P., Brain, P., 1999. The horizontal movement of seeds in arable soil by different soil cultivation methods. J. Appl. Ecol. 36, $443-454$.

Mayer, D.G., Butler, D.G., 1993. Statistical validation. Ecol. Model. 68, 21-32.

Mead, A., Grundy, A.C., Burston, S., 1998. Predicting the movement of seeds following cultivation. In: Champion, G.T., et al. (Eds.), Weed Seedbanks: Determination, Dynamics, and Manipulation. Aspects of Applied Biology 51, pp. 91-98.

Mead, A., Grundy, A.C., Brain, P., Marshall, E.J.P., 2003. Development of a model for the joint horizontal and vertical movement of seeds following cultivation. Aspects of Applied Biology 69, Seedbanks: Determination, Dynamics and Management, pp. 179-186.

Mohler, C.L., Frisch, J.C., McCulloch, C.E., 2006. Vertical movement of weed seed surrogates by tillage implements and natural processes. Soil Tillage Res. 86, 110-122.

Moss, S.R., 1988. Influence of cultivations on the vertical distribution of weed seeds in soil. In: Proceedings of the Eighth International Symposium on the Biology, Ecology and Systematics of Weeds, pp. 71-80.

Pareja, M.R., Staniforth, D.W., 1985. Distribution of weed seed among soil structure units. Weed Sci. 33, 182-189.

Pawlowski, F., Malicki, L., 1968. Effect of different methods of ploughing on vertical distributions of weed seeds in soil formed of loess. Annales Universitatis Mariae Curie-Sklodowska Lublin-Polonia 23, 161-174.

Pekrun, C., Lane, P.W., Lutman, P.J.W., 2005. Modeling seedbank dynamics of volunteer oilseed rape (Brassica napus). Agric. Syst. 84, 1-20.

Rahman, A., James, T.K., Mellsop, J., Grbavac, N., 2000. Effect of cultivation methods on weed seed disturbance and seedling emergence. New Zealand Plant Prot. 53, 28-33.

Reicosky, D.C., 1998. Strip tillage methods: impact on soil and air quality. In: Mulvey, P.J. (Ed.), Proceedings of the ASSSI National Soils Conference 1998. Brisbane, Australia, pp. 56-60.

Roberts, H.A., Feast, P.M., 1972. Fate of seeds of some annual weeds in different depths of cultivated and undisturbed soil. Weed Res. 12, 316-324.

Roberts, H.A., Ricketts, M.E., 1979. Quantitative relationships between weed flora after cultivation and the seed population in the soil. Weed Res. 19, 269-275.

Roberts, H.A., Chancellor, R.J., Thurston, J.M., 1977. Weed control handbook. In: Fryer, J.D., Makepeace, R.J. (Eds.), Weed Biology. Blackwell Scientific Publications, Oxford, UK, p. 127.

Roberts, H.A., Potter, M.E., 1980. Emergence patterns of weed seedlings in relation to cultivation and rainfall. Weed Res. 20, $377-386$.

Scopel, A.L., Ballare, C.L., Radosevich, S.R., 1994. Photostimulation of seed germination during soil tillage. New Phytol. 126, $145-152$.

Sheldon, J.C., 1974. The behaviour of seed in soil. III. The influence of seed morphology and the behaviour of seedlings on the establishment of plants from surface lying seeds. J. Ecol. 62, 47-66.

Stahl, L.A.B., Johnson, G.A., Wyse, D.L., Buhler, D.D., Gunsolus, J.L., 1999. Effect of tillage on timing of Setaria spp. emergence and growth. Weed Sci. 47, 563-570.

Staricka, J.A., Allmaras, R.R., Nelson, W.W., 1991. Spatial variation of crop residue incorporated by tillage. Soil Sci. Soc. Am. J. 55, $1668-1674$.

Straicka, J.A., Bufford, P.M., Allmaras, R.R., Nelson, W.W., 1990. Tracking the vertical distribution of simulated shattered seeds as related to tillage. Argon. J. 82, 1131-1134.

Sokal, R.R., Rohlf, F.J., 1981. Biometry, 2nd ed. W.H. Freeman \& Co, New York.

Soriano, A., Zeiger, E., Servy, E., Suero, A., 1968. The effect of cultivation on the vertical distribution of seeds in the soil. J. Appl. Ecol. 5, $253-257$.

Swanton, C.J., Shrestha, A., Knezevic, S.Z., Roy, R.C., Ball-Coelho, B.R., 2000. Influence of tillage type on vertical weed seedbank distribution in a sandy soil. Can. J. Plant Sci. 80, 455-457.

Toole, E.H., Brown, F., 1946. Final results of the Duvel buried seed experiment. J. Agric. Res. 72, 201-210.

Willmott, C.J., 1981. On the validation of models. Phys. Geogr. 2, 184-194.

Willmott, C.J., 1982. Some comments on the evaluation of model performance. Bull. Am. Meteor. Soc. 64, 1309-1313.

Yenish, J.P., Doll, J.D., Buhler, D.D., 1992. Effects of tillage on vertical distribution and viability of weed seed in soil. Weed Sci. 40, 429-433. 